\title{
Energy costs vs. carbon dioxide emissions in short-term production planning
}

\section{A business case study}

\author{
Andreas Dellnitz ${ }^{1}$ (D) - Damian Braschczok ${ }^{1}$. Jonas Ostmeyer ${ }^{1} \cdot$ Markus Hilbert $^{1}$. \\ Andreas Kleine ${ }^{1}$
}

(c) The Author(s) 2021, corrected publication 2021

\begin{abstract}
In energy-oriented lot-sizing and scheduling research, it is often assumed that minimizing energy costs automatically leads to an improvement of the ecological footprint of a company, i.e., lower carbon dioxide emissions. More precisely, a close to one (positive) correlation between energy costs and carbon dioxide emissions is often supposed. In this contribution, we show that this conjecture does not always hold true due to fluctuating carbon dioxide emissions over the whole day. Therefore, we present a real-world business case study, combining lot-sizing and machine scheduling under time-varying electric energy costs and carbon dioxide emissions in a mixed integer optimization model; in this context, we also consider on-site power generation. The interplay between all these aspects is demonstrated via a numerical analysis.
\end{abstract}

Keywords Energy costs $\cdot$ Carbon dioxide emissions $\cdot$ Multi-objective production planning $\cdot$ Sustainable manufacturing

JEL Classification C610

\section{Introduction}

\subsection{A first motivation}

The concept of sustainability or sustainable development has a long history and has been widely discussed in different contexts, especially in social, political and scientific contexts. According to Munda et al. (1994) one of the most widely accepted

Andreas Dellnitz

andreas.dellnitz@fernuni-hagen.de

1 FernUniversität in Hagen, Chair of Operations Research, P.O. Box 940, 58084 Hagen, Germany 
definitions dates back to 1987 and stems from the World Commission on Environment. Sustainable Development is, thus, "the paths of human progress which meet the needs and aspirations of the present generation without compromising the ability of future generations to meet their needs".

The scientific examination of sustainability is a complex challenge because especially the time aspect - the anticipation of the needs of future generations-leaves a lot of room for the interpretation of sustainable activity. It has been common to operationalize the term sustainability by connecting it with specific goals, depending on the context. In the production context, sustainability implies that the processes used to produce industrial products should be adjusted to reduce negative ecological influences as well as energy consumption, thus conserving natural resources. Furthermore, production processes should be safe and harmless for all stakeholders, and also be considered as "economically healthy", cf. Garetti and Taisch (2012), Haapala et al. (2013), Hong et al. (2012), Li et al. (2013).

If the reduction of energy consumption is seen as a primary goal, the operationalization of sustainability is often carried out via so-called energy efficiency, cf. Merkert et al. (2015), Giret et al. (2015), Mansouri et al. (2016). In general, efficiency describes an assessment criterion for the quality of a measure; here, the relationship between the output and input of an economic activity is often considered. According to Kleine and Ostmeyer (2018) and Fysikopoulos et al. (2014), the term energy efficiency refers to the ratio of the achieved output-e.g., the quantity produced-to the energy consumption-e.g., the amount of energy required to obtain the respective result. However, due to practical issues like the unavailability of appropriate measuring points, energy costs are often used instead of the actual energy consumption of particular processing steps.

One route to achieving a sustainable production in companies might be to improve energy efficiency, i.e., to increase the output or to reduce energy consumption or energy costs, cf. Jaehn (2016), Merkert et al. (2015), Kästner and Kießling (2016). However, the present work questions the common implicit conclusion that an improvement in energy efficiency leads to more sustainability in production. Our business case of a medium-sized metalworking company will demonstrate that sustainability and energy efficiency are not necessarily the same or complementary goals. More precisely, from an operational point of view, we show that carbon dioxide emissions can increase when decreasing energy costs by resizing and reallocating operational activities over a production week. Hence, there can be a trade-off between both aims and prudent management should pay heed to these effects.

The theoretical basis for this observation is related to previous work in the field of energy-efficient production planning (EEPP). In the classification scheme of Biel and Glock (2016), the authors distinguish between energy-efficient lot sizing and energy-efficient scheduling of machines within the short-term EEPP. In this paper, a multi-criteria optimization model is presented that simultaneously takes both planning tasks into account by considering the minimization of energy costs as well as average carbon dioxide emissions. From a model-theoretical point of view, our study is, thus, closely related to the work of Wichmann et al. (2019), Johannes et al. (2018), and Masmoudi et al. (2016) because they also minimize energy-driven goals in the context of lot sizing and scheduling problems. From a pure energy-efficient 
scheduling perspective, our work can be linked to Mouzon and Yildirim (2008), Moon et al. (2013), Rager et al. (2015) and Wang et al. (2015)—we also consider unrelated machines in parallel. However, the energy demand-side management of production processes (cf. Gahm et al. (2016)) and the minimization of power peaks by shifting energy-intensive production steps to periods with lower electricity prices (see e.g. Buscher et al. 2016; Keller et al. 2015; Bego et al. 2014; Reinhart et al. 2012) are well-known measures to rapidly improve energy efficiency. It is often assumed that a decrease in energy consumption and/or energy costs leads to a decline in carbon dioxide emissions (cf. Jaehn (2016)). However, our case study will show that this is not necessarily true; for a first hint regarding this issue see also Li et al. (2018). Therefore, our novel approach is to consider fluctuating average carbon dioxide emissions and electricity prices simultaneously in a lot sizing and scheduling environment. The next section highlights the interplay between average carbon dioxide emissions and electricity prices more transparent.

\subsection{Electricity market prices vs. average carbon dioxide emissions}

As mentioned in the motivation, it is often assumed that minimizing energy-oriented objective functions automatically leads to more sustainable production plans, decreasing, e.g., carbon dioxide emissions. However, assuming such a causal link is questionable, and this section provides evidence regarding this issue (also refer to Li et al. (2018)). The question "what are the electricity mix and the corresponding average carbon dioxide emissions at a specific point in time?" might give a first orientation. To answer this question, we provide Fig. 1-the hourly electricity mix data for the work week dating from 24 Sep 2018 to 28 Sep 2018; refer to the energy charts (https://www.energy-charts.de) of the Fraunhofer-Institut für Solare Energiesysteme (ISE).

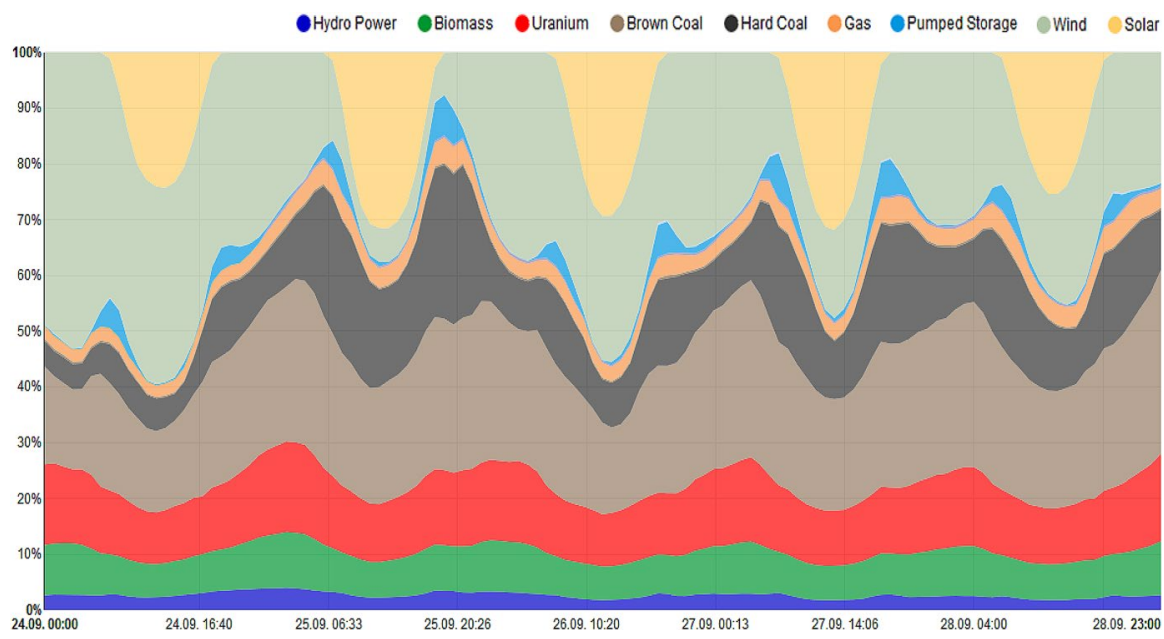

Fig. 1 Relative mix of electricity production in Germany 
As one can see, the electricity mix varies strongly from $1 \mathrm{~h}$ to another. In particular, the relative importance of solar and wind energy decreases during the night. Besides nuclear power, coal-fired power production becomes more attractive at night (off-peak, $10 \mathrm{pm}-8 \mathrm{am}$ ) than ramping up gas-fired power plants due to lower marginal costs. This observation merely summarizes current economic facts of conventional energy generation, i.e., merit order-based operational planning. Considering the ecological footprint, however, it is preferable to produce within the power peak periods $(8 \mathrm{am}-10 \mathrm{pm})$ because injection rates of renewables are highest then. To underpin this, we calculate the average $\mathrm{CO}_{2}$ emissions per hour, determining the weighted average emissions $[\mathrm{kg} / \mathrm{kWh}$ ] of power plants based on the given electricity mix data; for details regarding the data refer to the homepage of the German Federal Environmental Agency (https://www.umweltbundesamt.de). Figure 2 shows the results and the corresponding hourly spot prices [EUR/kWh] from the EPEX SPOT SE (European Power Exchange, https://www.epexspot.com). Here again, we present the weekly data from 24-28 Sep 2018. One important aspect of this week is that it does not include any one-off effects and, hence, might be a veritable proxy for a normal business week; this data will be used in our business case study because it corresponds to the production period in our business case.

Figure 2 supports our assumption, but it needs further explanation. As a first indicator, one can take the period in the shaded area. Here, the market price is very low at night, but the average carbon dioxide emissions are considerably higher at night than during the day. In order to explore these relationships more systematically, we split the days into peak periods ( $8 \mathrm{am}-10 \mathrm{pm})$ and off-peak periods $(10 \mathrm{pm}-8 \mathrm{am})$, thus determining the correlation between market prices and emissions. For the peak periods, we obtain a moderate positive correlation of 0.6038 , and for the off-peaks, we obtain a positive correlation of only 0.3672 . Obviously, there is no one-to-one relationship, i.e., these numbers might indicate the occurrence of a potential conflict between minimizing energy costs and carbon dioxide emissions; see also Li et al. (2018).

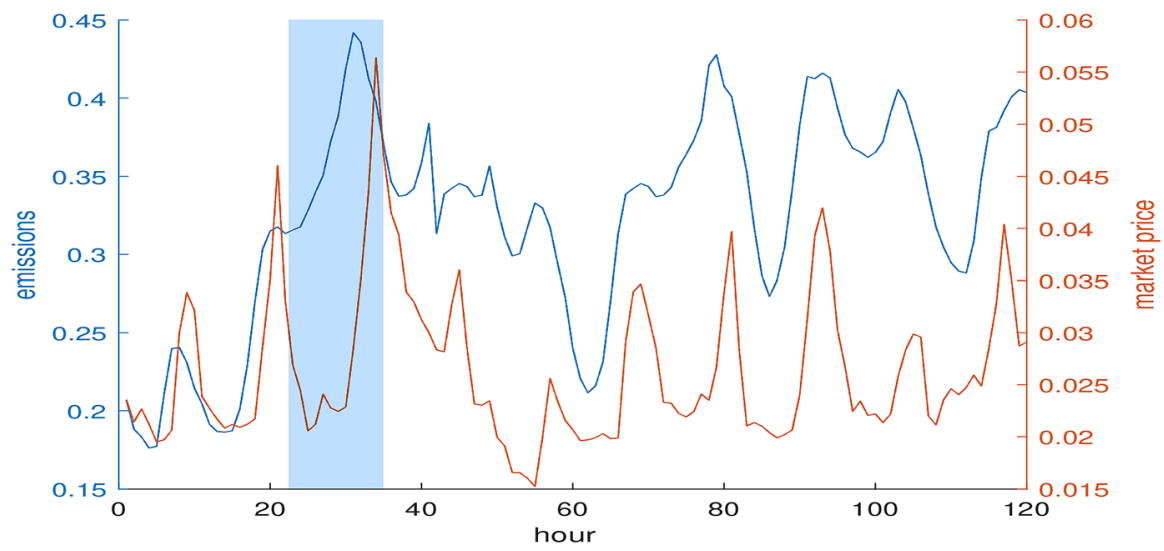

Fig. 2 Average emissions vs. electricity market prices 
To put it plainly, the electricity generation costs of gas power plants are higher than those of coal-fired power plants, yet for the emissions, the opposite is true; for a justification refer to Kost et al. (2018). Renewable energies are, of course, 'greenest' and marginal costs here are generally considered to be very low, but the respective energy output is determined by volatile exogenous factors. These facts imply that if the electricity price continues to increase, it will become more attractive to ramp up cleaner power generation plants such as gas power plants. In summary, the above figures might give a first hint that an energy-efficient production plan does not automatically imply a sustainable one and vice versa; this is in sharp contrast, e.g., to Gong et al. (2015). This conflict can be heightened further when additionally considering on-site power generation via alternative energy sources. In the long run, these statements will, obviously, become obsolete if renewable energies fully substitute the remaining nuclear and conventional power plants. However, in the short run, our findings should be considered in a rationality-driven decision-making process. To make possible trade-offs more transparent in the context of short-term production planning, we discuss such effects by means of an illustrative example and a realworld business case in the next sections.

The remainder of the paper is organized as follows: first of all, the potential tradeoff between sustainability and energy efficiency has to be examined in-depth in Sect. 2. Next, we present our case study in Sect. 3, including the introduction of the optimization problem, the presentation of numerical results and a critical discussion. Case-related takeaways for the management of similar industrial companies are also presented in this section. Sect. 4 concludes this paper with a brief summary of our main results and a short outlook.

\section{Short-term production planning-the trade-offs}

In the previous section, we discussed the relationship between average carbon dioxide emissions and electricity market prices. However, this analysis has left one essential question unanswered: What does this mean for short-term production planning? To answer this question and to make the indicated trade-offs more accessible, we present an illustrative example. Figure 3 shows an arbitrary path of machine states - off mode $(i=0)$, changeover $(i=1)$, ramp up $(i=2)$, test run $(i=3)$, standby $(i=4)$, and production $(i=5)$ - and the corresponding energy

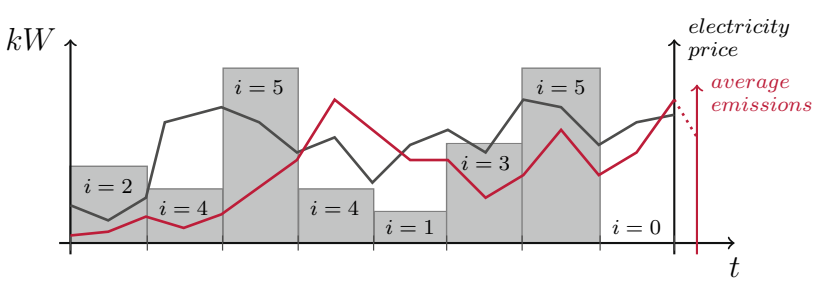

Fig. 3 Machine states, electricity prices and average emissions 


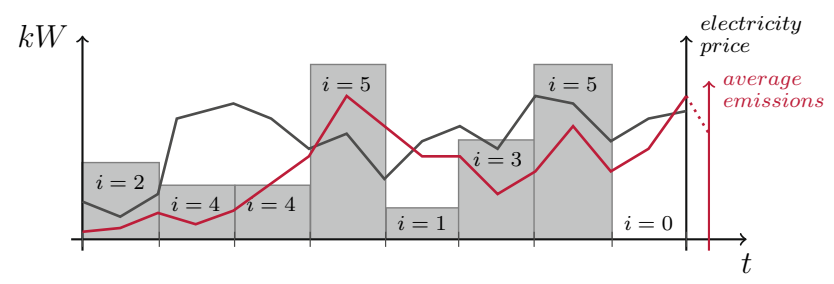

Fig. 4 Energy price-driven rescheduling

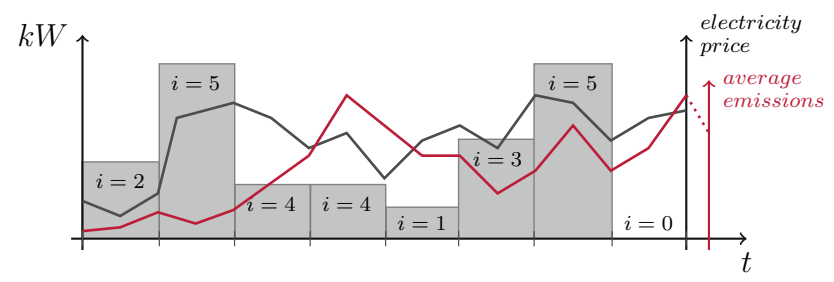

Fig. 5 Emission-driven rescheduling

consumptions. Furthermore, the black curve shows an electricity price curve and the red one the associated average emissions. In this illustrative example, both production states $(i=5)$ take place at price peaks; in contrast to the second production state, the first production state seems to be favorable in terms of average emissions.

The next figure presents an energy price-driven rescheduling of the first production state. This means, if we face a period with relatively high energy prices, we try to shift our production state to cheaper periods in order to minimize energy costs if possible. Therefore, we swapped the first production state with the standby state. Obviously, this shift leads to decreasing energy costs because now the production - the state with highest energy consumption-takes place at more moderate electricity prices; however, the average emissions reach their maximum in this period (Fig. 4).

Evidently, this trade-off might be acceptable if the management primarily focusses on profit-oriented targets. From an ecological footprint perspective, this shift appears to be unreasonable. Therefore, we provide Figure 5 to show the reverse picture. Now, as in the first figure, we produce in a very expensive period of time, yet at minimum average emissions.

The trade-off shown above is primarily demonstrated via shifting operations, i.e., it is based on scheduling production activities. Yet, what are the consequences if lotsizing comes into play? The answer is very straightforward: when considering only one of the aforementioned two perspectives, then the other component-either the production's energy costs or average emissions-will further deteriorate due to the increased flexibility in the allocation of resources.

Accordingly, we provide the following two definitions to render more precisely the two-possibly competing_objectives: 
Definition 1 A short-term production plan is called energy efficient if it is executed at minimal energy costs.

Definition 2 A short-term production plan is called operationally sustainable if it is executed at minimal carbon dioxide emissions.

Of course, measuring or determining carbon dioxide emissions is a complex issue in practice. Emissions, a strong fluctuation of power generation from renewable energies, and associated changes for the industry are interrelated problems which are reflected by the challenging electricity trading in Germany, cf. Graeber and Kleine (2013). Here, the structural composition of the German electricity market (the electricity mix), network stability, market price developments, and the influence of energy policy decisions are intensively researched topics, see e.g. Paraschiv et al. (2014) and Wozabal et al. (2016). Due to our operational focus, we take these market situations as given and operate with historically observed energy market prices in order to show the potential of our novel multi-criteria optimization model. In doing so, we check for potential gains when entering into energy contracts involving real-time pricing without the background noise of any forecasting tool.

\section{Energy costs vs. average $\mathrm{CO}_{2}$ emissions: a case study}

\subsection{The business case}

In our operational planning case, we need to determine a production plan to finish a set of jobs on a set of machines considering multiple objectives. In order to obtain a final plan, it is important to fathom the impact of such goals from a technical, economic, and ecological perspective. First of all, we give the main assumptions of the underlying production environment: we consider

- a single stage, multi-product production process,

- (four) unrelated machines in parallel,

- finite and constant production speed,

- deterministic (weekly) demand data,

- a finite planning horizon (one work week comprising three shifts).

In our business case, we are given a metal-working company which bends metal on unrelated machines in parallel; i.e., the machines are identical with respect to their processing times but heterogeneous regarding electric energy consumption. Furthermore, the machines do not deteriorate over time. The machines are working in threeshift operation-eight hours per shift—and can be set up and operated over a period of five days. Additionally, the company produces seven product groups or jobs; but each machine can only handle a subset of all such groups. Notably, the setup process constitutes a special issue: to make the machines ready, one needs a full shift of $8 \mathrm{~h}$. 
Table 1 Feasible assignments $\gamma_{j m}^{\text {asgn }}$

\begin{tabular}{lllll}
\hline & $m=1$ & $m=2$ & $m=3$ & $m=4$ \\
\hline$j=1$ & 1 & 1 & 1 & \\
$j=2$ & 1 & 1 & 1 & \\
$j=3$ & 1 & & 1 \\
$j=4$ & & 1 & 1 \\
$j=5$ & 1 & 1 & 1 \\
$j=6$ & & & & \\
$j=7$ & & & & \\
\hline
\end{tabular}

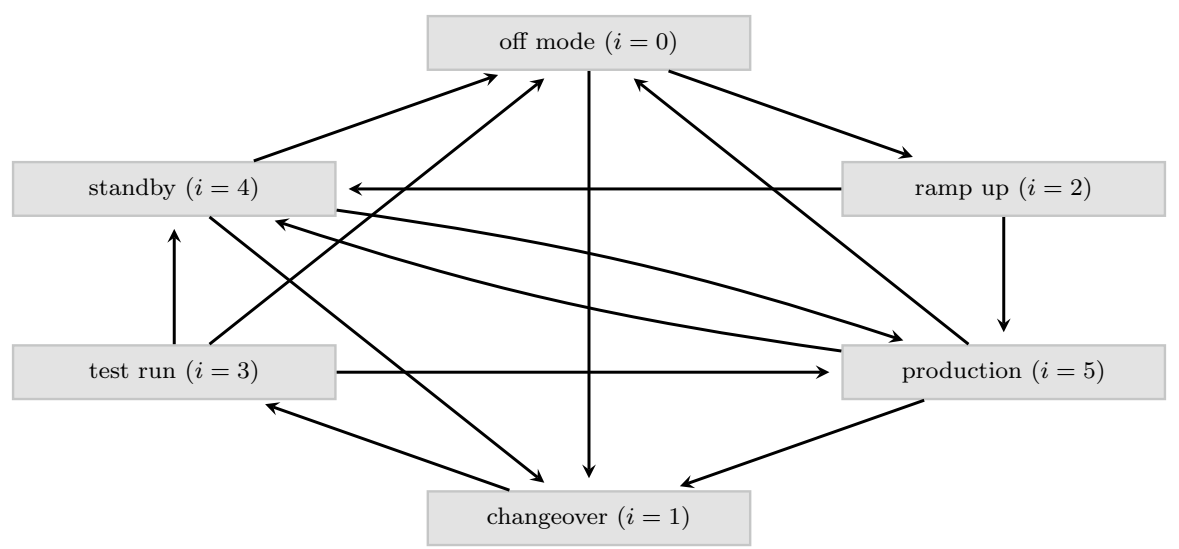

Fig. 6 Feasible states and transitions

More precisely, we consider a set of jobs $\mathcal{J}=\{1, \ldots, J\}$, with $J=7$, which can be produced on a set of unrelated (parallel) machines $\mathcal{M}=\{1, \ldots, M\}$, with $M=4$, in the periods $t$, where each $t$ represents $1 \mathrm{~h}$ and $t \in \mathcal{T}=\{0, \ldots, T\}$ with $T=120$; where $t=0$ determines the initialization state and $t>0$ the actual planning horizon. Unrelated and parallel here means we suppose that each job $j \in \mathcal{J}$ can be realized only on a subset $\mathcal{M}_{j}$ of all production units $\mathcal{M}_{j} \subset \mathcal{M}=\{1, \ldots, M\}$, considering the same processing time for all jobs regardless of the machine equipment; Table 1 shows respective feasible assignments.

Additionally, there are three features which make our business case more sophisticated:

- Each machine $m \in \mathcal{M}$ can have different states $i \in \mathcal{I}=\{0, \ldots, I\}$, with $I=5$, and a transition into another state $h$ only depends on the current state $i$. To illustrate this, in Fig. 6, we show a dependency graph consisting of the six machine states and the respective feasible transitions-directions are indicated by arrows. This means, if there is an arrow from node $i$ to $h$, then a state transition is feasible and the edge weight $\gamma_{i h}^{\text {tran }}$ equals 1 ; otherwise the weight is zero. 


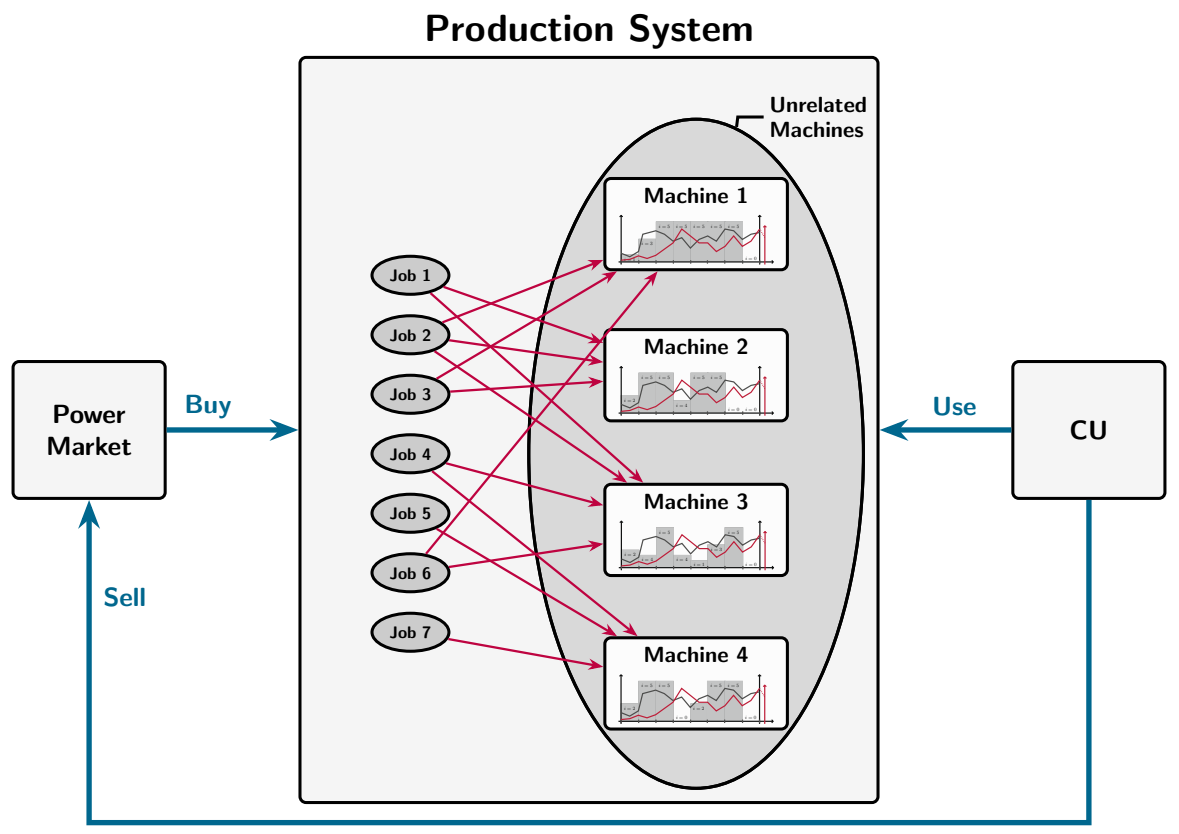

Fig. 7 Business case environment

- Each machine $m \in \mathcal{M}$ consumes an individual amount of electric energy $a_{i m}^{\text {elec }}$ depending on its state, as illustrated by Figs. 3, 4, 5; here, the superscript elec is used to identify the resource that we deal with-electrical energy.

- Additionally, in line with our business case, we consider on-site generation of electric energy via a so-called cogeneration unit (CU). Such a unit converts gas into heat energy and electricity. Particularly interesting is the fact that in each period, we can sell the self-generated electricity or we can use it —or a combination of both. This $\mathrm{CU}$ can be operated at different energy generation modes: $\ell=1$ relates to the off mode, and the conversion efficiency $r_{\ell}$ of the states $\ell=2, \ell=3$ as well as $\ell=4-$ varies between 0.31 and 0.36 . This means $r_{\ell}$ converts the gas units (input of $\mathrm{CU}$ in cubic metre) to electricity units (output of $\mathrm{CU}$ in kilowatt hours). The states $\ell \in \mathcal{L}$ refer to the corresponding operational intensity, i.e., $\ell=2$ refers to a 0.5 capacity utilization, $\ell=3$ a 0.75 intensity, and $\ell=4$ a full capacity utilization 1 .

Figure 7 summarizes the core elements of our business case environment.

The next section details the business case-based multi-objective optimization problem. 
Table 2 Indices and descriptions

\begin{tabular}{ll}
\hline Symbol & Specification \\
\hline$m$ & Machine $m \in \mathcal{M}=\{1, \ldots, 4\}$ \\
$i, h$ & Machine state $i, h \in \mathcal{I}=\{0, \ldots, 5\}$ \\
$j, g$ & job $j, g \in \mathcal{J}=\{1, \ldots, 7\}$ \\
$\ell$ & State of the cogeneration unit $\ell \in \mathcal{L}=\{1, \ldots, 4\}$ \\
$t, \tau$ & period (a working hour) $t, \tau \in \mathcal{T}=\{0, \ldots, 120\}$ \\
\hline
\end{tabular}

Table 3 Parameters and descriptions

\begin{tabular}{ll}
\hline Symbol & Specification \\
\hline$a_{j}^{\text {prod }}$ & Production output for job $j$ per period $t$ \\
$a_{i m}^{\text {elec }}$ & Electricity consumption of machine $m$ in state $i$ \\
$B$ & Big number \\
$c_{t}^{\text {elec }}$ & Cost rate [per $\mathrm{kWh}$ ] of the electric energy purchased in $t$ \\
$c^{\text {le }}$ & Cost rate [per $\mathrm{kW}]$ when breaching the agreed energy peak demand, so-called Leistungsentgelt \\
$c^{\text {th }}$ & Penalty fee when exceeding the materiality threshold \\
$d_{j}$ & Demand of job $j$ to be fulfilled \\
$e_{t}^{\text {elec }}$ & CO ${ }_{2}$ emission $[\mathrm{kg} / \mathrm{kWh}$ of the electricity mix purchased in $t$ \\
$\gamma_{j m}^{\text {asgn }}$ & If $m \in \mathcal{M}$, then $\gamma_{j m}^{\text {asgn }}$ equals 1 and an assignment of job $j$ to machine $m$ is feasible \\
$\gamma_{i h}^{\text {tran }}$ & Transition from machine state $i$ to $h$ \\
$\rho_{j}$ & Number of parallel machines for processing job $j$ \\
$b^{\text {thresh }}$ & Materiality threshold $[\mathrm{kWh]} \mathrm{to} \mathrm{reduce} \mathrm{grid} \mathrm{charges,} \mathrm{so-called} \mathrm{Erheblichkeitsschwelle}$ \\
$b^{\text {tot }}$ & Total amount $[\mathrm{kWh]} \mathrm{of} \mathrm{contractually} \mathrm{agreed} \mathrm{electrical} \mathrm{energy}$ \\
$b_{\ell}^{\text {elec }}$ & Max. amount of electricity from cogeneration in state $\ell$ \\
$c_{t}^{\text {gas }}$ & Cost rate [per $\mathrm{kWh}$ of the gas purchased in $t$ \\
$e^{\text {gas }}$ & CO ${ }_{2}$ emission $[\mathrm{kg} / \mathrm{kWh]} \mathrm{of} \mathrm{the} \mathrm{cogeneration} \mathrm{unit}$ \\
$p_{t}^{\text {elec }}$ & Price [per $\mathrm{kWh}$ of the electricity sold in $t$ \\
$r_{\ell}$ & Conversion efficiency of the cogeneration unit in state $\ell$ \\
\hline
\end{tabular}

\subsection{The business case-related multi-objective optimization problem}

As already mentioned, the processing of a job on a machine requires that the respective machine is prepared. This means, we need to opt for the set up of machines, necessary changeovers and the lengths of the production periods. This timing issue, obviously, is directly related to the decision on energy consumption. To make the entire optimization problem and equations more perspicuous, we first give all indices, parameters, and decision variables in tabular form; see Tables 2, 3 and 4.

Next, we present our business case-driven multi-objective optimization problem, which is defined by Eq. (1)-(22). Here, four objectives are taken into account: roughly speaking, we optimize production quantities $D$, a time-related goal $Y$, operational energy costs $C$, and the carbon dioxide emissions $E$. We do not consider other 
Table 4 Decision variables and descriptions

\begin{tabular}{ll}
\hline Symbol & Specification \\
\hline$d_{j}^{-}$ & Production shortfall for job $j$ (backlogs) \\
$d_{j}^{+}$ & Production excess for job $j$ \\
$s_{t}^{\text {buy }}$ & kWh amount of electricity purchased in $t$ \\
$x_{j m t}$ & (Job assignment) binary equals 1 if job $j$ will be processed on machine $m$ in period $t$, otherwise \\
& 0. \\
$\delta_{\text {imt }}^{\text {state }}$ & (Machine state) binary equals 1 if machine $m$ has state $i$ in period $t$, otherwise 0. \\
$\delta_{j m t}^{\text {setup }}$ & (Machine setup) binary equals 1 if machine $m$ can produce job $j$ in period $t$, otherwise 0. \\
$\delta_{j g m t}^{\text {change }}$ & (Machine changeover) binary equals 1 if the retooling of machine $m$-to produce $g$ instead of \\
$\Delta s^{\text {tot }}$ & $j$-has to be started in period $t$, otherwise 0. \\
$\Delta s^{\text {thresh }}$ & Excess of contractually agreed energy amount $b^{\text {tot }}$ \\
$s_{t}^{\text {self }}$ & Excess of materiality threshold $b^{\text {thresh }}$ \\
$s_{t}^{\text {sell }}$ & $\mathrm{kWh}$ Amount of electricity self-generated in $t$ \\
$z_{\ell t}$ & $\mathrm{kWh}$ Amount of electricity sold in $t$ \\
\hline
\end{tabular}

operational costs, such as personnel and/or material costs because in our business case these numbers are fixed over the working week. However, the model below can be easily modified to exploit cost savings potentials for such factors, of course. Furthermore, we are given deterministic demand, energy prices and emission mixes over the respective planning period. Additionally, we assume perfect production processes, i.e., the machines do not deteriorate over time, and due dates are also not considered.

$$
\begin{gathered}
\min \quad D=\sum_{j=1}^{J} d_{j}^{+}+d_{j}^{-} \\
\min \quad Y=\sum_{m=1}^{M} \sum_{t=0}^{T}\left(\delta_{1 m t}^{\text {state }}+\delta_{3 m t}^{\text {state }}\right) \\
\min \quad \sum_{t=0}^{T}\left(c_{t}^{\text {elec }} \cdot s_{t}^{\text {buy }}-p_{t}^{\text {elec }} \cdot s_{t}^{\text {sell }}\right)+c^{\text {le }} \cdot \Delta s^{\text {tot }} \\
+\sum_{\ell=1}^{L} \sum_{t=0}^{T}\left(c_{t}^{\text {gas }} \cdot \frac{b_{\ell}^{\text {elec }}}{r_{\ell}} \cdot z_{\ell t}\right)+c^{\text {th }} \cdot \Delta s^{\text {thresh }} \\
\min \quad \sum_{t=0}^{T} e_{t}^{\text {elec }} \cdot s_{t}^{\text {buy }}+\sum_{\ell=1}^{L} \sum_{t=0}^{T}\left(e^{\text {gas }} \cdot \frac{b_{\ell}^{\text {elec }}}{r_{\ell}} \cdot z_{\ell t}\right)
\end{gathered}
$$




$$
\begin{aligned}
& \text { s.t. } \quad \sum_{j=1}^{J} x_{j m t} \leq 1 \quad \forall m, t \\
& \sum_{m=1}^{M} x_{j m t} \leq \rho_{j} \quad \forall j, t \\
& \sum_{m=1}^{M} \sum_{t=0}^{T}\left(a_{j}^{\text {prod }} \cdot x_{j m t}\right)-d_{j}^{+}+d_{j}^{-}=d_{j} \quad \forall j \\
& \sum_{i=0}^{I} \delta_{i m t}^{\text {state }}=1 \quad \forall m, t \\
& x_{j m t}-\delta_{5 m t}^{\text {state }} \leq 0 \quad \forall j, m, t \\
& \delta_{\text {im, } t-1}^{\text {state }}-\delta_{\text {imt }}^{\text {state }}+\delta_{\text {hmt }}^{\text {state }} \leq 1+\gamma_{\text {ih }}^{\text {tran }} \quad \forall i, h \neq i, m, t \in \mathcal{T} \backslash\{0\} \\
& \sum_{j=1}^{J} \delta_{j m t}^{\text {setup }}=1 \quad \forall m, t \\
& x_{j m t}-\gamma_{j m}^{\text {asgn }} \cdot \delta_{j m t}^{\text {setup }} \leq 0 \quad \forall j, m, t \\
& \delta_{j m, t-1}^{\text {setup }}+\delta_{\text {gmt }}^{\text {setup }}-\delta_{\text {jgmt }}^{\text {change }} \leq 1 \quad \forall j, g \neq j, m, t \\
& \sum_{j} \sum_{g \neq j} \delta_{j g m t}^{\text {change }} \leq 1 \quad \forall m, t \\
& \delta_{\text {jgmt }}^{\text {change }}-\frac{1}{8} \cdot\left(\sum_{\tau=t}^{t+4} \delta_{1 m \tau}^{\text {state }}+\sum_{\tau=t+5}^{t+7} \delta_{3 m \tau}^{\text {state }}\right) \leq 0 \quad \forall j, g \neq j, m, t \in \mathcal{T}^{\text {hift }} \\
& \delta_{\text {jgmt }}^{\text {change }}=0 \quad \forall j, g \neq j, m, t \in \mathcal{T} \backslash \mathcal{T}^{\text {shift }} \\
& \sum_{\ell=1}^{L} z_{\ell t}=1 \quad \forall t
\end{aligned}
$$




$$
\begin{gathered}
\left(s_{t}^{\text {sell }}+s_{t}^{\text {self }}\right)-\sum_{\ell=1}^{L}\left(b_{\ell}^{\text {elec }} \cdot z_{\ell t}\right)=0 \quad \forall t \\
\sum_{i=0}^{I} \sum_{m=1}^{M}\left(a_{\text {im }}^{\text {elec }} \cdot \delta_{\text {imt }}^{\text {state }}\right)-\left(s_{t}^{\text {buy }}+s_{t}^{\text {self }}\right)=0 \quad \forall t \\
s_{t}^{\text {buy }}-\Delta s^{\text {tot }} \leq b^{\text {tot }} \quad \forall t \\
s_{t}^{\text {buy }}-B \cdot \Delta s^{\text {thresh }} \leq b^{\text {thresh }} \quad \forall t \in \mathcal{T}^{\text {peak }} \\
x_{j m t}, \delta_{\text {imt }}^{\text {state }}, \delta_{j m t}^{\text {setup }}, \delta_{j g m t}^{\text {change }}, \Delta s^{\text {thresh }}, z_{\ell t} \in\{0,1\} ; \\
d_{j}^{+}, d_{j}^{-}, s_{t}^{\text {buy }}, s_{t}^{\text {self }}, s_{t}^{\text {sell }}, \Delta s^{\text {tot }} \geq 0
\end{gathered}
$$

In order to meet the production demand, we minimize deviations from the amount requested per week for each job; it is due to the fact that the production capacity available may not meet the demand. This is what the first objective function is about.

Applying the second objective function, we minimize the total amount of time spent on a very special setup process, which consists of changing equipment configurations and testing product quality. Obviously, this is not a classical time-related scheduling objective; it stems from our business case because the whole gearing up process consumes an eight-hour work shift. Still, one can easily replace this function by, e.g., makespan or cycle time, if desired. For a good overview of classical timerelated objectives, see e.g. Pinedo (2016, pp. 19-20).

The third objective function corresponds to Definition 1 and pursues the aim of minimizing the total energy costs. Here, the first term refers to the amount of energy $s_{t}^{\text {buy }}$ which will be bought on the market, where $c_{t}^{\text {elec }}$ is the energy price depending on the period $t$. Additionally, we have to subtract the amount of the self-produced electricity $s_{t}^{\text {sell }}$ that we sell on the market for the price $p_{t}^{\text {elec }}$. The next component refers to excess of the contractually agreed amount of electrical energy where the costs or penalty fees come from the utility contract. As already mentioned in Sect. 3.1, the cogeneration unit (CU) operates at different states $\ell \in \mathcal{L}=\{1, \ldots, L\}$, with $L=4$. The total costs of the conversion process of the $\mathrm{CU}$ are determined by the double sum. $c_{t}^{\text {gas }}$ is the the cost coefficient for one kilowatt hour gas, the fraction $\frac{b_{\ell}^{\text {elec }}}{r_{\ell}}$ captures the maximal output $b_{\ell}^{\text {elec }}$ adjusted via the conversion efficiency $r_{\ell}$, and $z_{\ell t}$ is the corresponding binary variable for switching between the various states. But keep in mind that if we reach the off mode $(\ell=1)$, we get $r_{\ell}=0$ and, hence, $\frac{b_{\ell}^{\text {elec }}}{r_{\ell}}$ becomes meaningless. In such a case, we set $\frac{b_{\ell}^{\text {elec }}}{r_{\ell}}=0$. Furthermore, to save grid costs, we are looking for an atypical profile of energy consumption with the last term in (3) - socalled atypical network usage. Here, atypical network usage means that we need to keep our energy consumption below $b^{\text {thresh }}$ in certain periods. These periods are, on 
principle, stipulated by the network operator and coincide with high levels of network capacity utilization.

With the fourth objective function, according to Definition 2, we track the emissions of the production process with respect to the total energy consumption. It measures the emissions $e_{t}^{\text {elec }}$ regarding the electrical energy purchased; here, the emissions depend on $t$. The second part measures the CU's emissions by the double sum in (4), where the emission coefficient $e^{\text {gas }}$ is independent of $t$.

The constraint (5) simply guarantees that one machine can only handle one job, but we can finish one job on multiple machines in parallel if $\rho_{j}>1$, refer to (6).

Equation (7) covers the product demand for all jobs, where $d_{j}$ specifies the number of goods corresponding to each job $j$ and the fraction $\frac{d_{j}}{a_{j}^{\text {rrod }}}$ the length for each job $j$ operated continuously. In this context, we allow over- and underproduction (stocks and backlogs) to equate demand quantities $d_{j}$. Obviously, over- and underproduction depend on the data of a specific instance, and the latter case is more likely if demand $d_{j}$ is high for each job. However, overproduction can also happen when, e.g., $\frac{d_{j}}{a_{j}^{p r o d}}$ is not integral.

Equation (8) prevents machines from becoming stateless. However, we can only get a job done on a machine when it is already prepared for production (state $i=5$ ); this is what inequality (9) is about. In order to control state transitions on machines, we give Eq. (10). Here, one can hold the state $\delta_{i m, t-1}^{\text {state }}=\delta_{\text {imt }}^{\text {state }}=1$ or we can change it $\delta_{i m, t-1}^{\text {state }}=\delta_{h m t}^{\text {state }}=1$. The latter case is only possible if the parameter $\gamma_{i h}^{\text {tran }}$ equals 1 ; for feasible transitions see again Fig. 6.

In every period, each machine must always be prepared for any arbitrary jobmore precisely, we cannot have a toolless situation, confer (11). To produce goods, we need the correct equipment, see (12). Furthermore, we apply equation (13) to steer the equipment changeovers. The operating principle of this group of restrictions is similar to that of (10), but we can perform only one changeover on a machine, hence (14) is necessary. The next Eq. (15) looks slightly more complicated, but it ensures that a changeover will be completed without replacing the staff. In our business case, the issue is that a changeover takes an entire shift, i.e. eight hours: five hours for changing the equipment and three hours for testing the quality of products. This justifies the very special paremeters in (15). To avoid staff changes during a changeover, one has to start at the beginning of a work shift; these points in time are defined by the set $\mathcal{T}^{\text {shift }}=\{1,9,17,25,33,41,49,57,65,73,81,89,97,105,113\} \subset \mathcal{T}$. Of course, constraint (15) can easily be adapted to other situations by merely modifying respective numbers. Via equation (16) we suppress undesired changeovers.

Equations (17) and (18) model the operational deployment of the CU. The CU cannot be stateless, see (17), and we can either sell $s_{t}^{\text {sell }}$ or use $s_{t}^{\text {self }}$ the total amount of self-generated energy, refer to (18). It is important to cover the electricity demand of all machines. Therefore, we need an energy balance equation like in (19). Inequalities (20) and (21) capture deviations of two electricity bounds. The first bound is based on a contractual agreement and can be violated; yet, in such a case, the company will be penalized by $c^{l e}$ per unit of $\Delta s^{t o t}$. The second one is an intragroup bound to participate in a program of the German Federal Network Agency that offers 
individual grid charges when not breaching a specific energy amount in pre-defined peak load time windows $\mathcal{T}^{\text {peak }}=\{14,15,38,39,62,63,86,87,110,111\} \subset \mathcal{T}$, in Germany also known as Hochlastzeitfenster; more on that topic can be found in StromNEV (2005). The company will lose its cost savings $\left(c^{\text {th }}\right)$ if the respective bound is violated. A violation is indicated by the binary $\Delta s^{\text {thresh }}$, and to control respective behavior in (21), we need the big number $B$. Constraints (22) are classical binary and nonnegativity restrictions.

Solving multi-objective optimization problems as given above is a difficult task. The problem here is that if the goals are conflicting, we do not have one optimal solution regarding all objective functions - there might be a trade-off between them; and due to our observations in Sect. 2, it is not obvious whether the above objective functions are conflicting or not. Consequently, the decision-maker has to choose one optimal solution from possibly an infinite number of optimal solutions, generally known as Pareto-optimal solutions. In our case study, the decision makers have the following preferences regarding the objective functions $D>Y \geqslant C \geqslant E$. This means that the company here primarily seeks to meet production demand. Next, the company will avoid spending much time and effort on changeovers and test runs, energy costs, peak loads, and carbon emissions. Yet, to get a more in-depth look into the trade-offs of these four- possibly competing —objectives, we additionally seek to check for different weight compositions. Therefore, to fathom the optimization problem without precluding Pareto-optimal solutions which are not part of the convex hull of the feasible region, we opt for a Chebyshev approach that minimizes the weighted maximal deviation from all individual optimal solutions. In this context, we always obtain a weak efficient solution given the fact that the weights $w^{D}, w^{Y}, w^{C}$ and $w^{E}$ are strictly positive; for further details see Ehrgott (2005)—especially proposition 4.22 on page 114 - and for an overview of theoretical aspects of multicriteria optimization T'kindt and Billaut (2006, pp. 53-112) and again Ehrgott (2005). Ultimately, we solve

$$
\begin{array}{clr}
\min z=g & \\
\text { s.t. } & w^{D} \cdot \frac{D-D^{\min }}{D^{\max }-D^{\min }} & -g \leq 0 \\
& w^{Y} \cdot \frac{Y-Y^{\min }}{Y^{\max }-Y^{\min }} & -g \leq 0 \\
& w^{C} \cdot \frac{C-C^{\min }}{C^{\max }-C^{\min }} & -g \leq 0 \\
& w^{E} \cdot \frac{E-E^{\min }}{E^{\max }-E^{\min }} & -g \leq 0 \\
& \text { plus constraints (5) to (22) }
\end{array}
$$

The normalization of the mathematical terms of previous objective functions in Eq. (23) is necessary to eliminate effects caused by units of different dimensions when fathoming the goals' trade-offs, cf. Steuer (1986, p. 201). The reference levels are given by minimum and maximum values for each objective function (1)-(4). However, the issue now is that we do not know the reference levels to implement the above corrections. Therefore, we propose a two-stage optimization procedure:

1. First, minimize and maximize each single goal to obtain $D^{\min }, D^{\max }, Y^{\min }, Y^{\max }$, $C^{\min }, C^{\max }, E^{\min }, E^{\max }$. 
Table 5 Relative proportions of demand

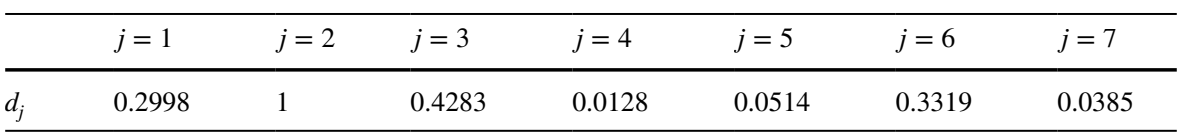

Table 6 Relative proportions of output coefficients

\begin{tabular}{|c|c|c|c|c|c|c|c|}
\hline & $j=1$ & $j=2$ & $j=3$ & $j=4$ & $j=5$ & $j=6$ & $j=7$ \\
\hline$a_{j}^{\text {prod }}$ & 0.0163 & 0.0054 & 0.0114 & 0.1375 & 0.0344 & 0.0161 & 0.0458 \\
\hline
\end{tabular}

2. Second, optimize Eq. (23) by applying the optimal values of the first stage and the desired weighting schemes.

Now, all the fundamentals are in place to study the real-world application in the next section.

\subsection{Further parameter specifications and scenarios}

In our case study, as already mentioned in Sect. 3.1, we consider a metal-working company, which bends metal on four machines. The exact amounts of the maximum output per hour $a_{j}^{\text {prod }} \forall j$ and the state-dependent energy consumption rates $a_{i m}^{\text {elec }} \forall i, m$ of the machines, as well as the total demand $d_{j} \forall j$ are not reported-for reasons of confidentiality. However, in order to guarantee reproducibility of the results presented subsequently, we give relative numbers.

The most important product group is the second one, as one can see in Table 5, $j=4, j=5$ and $j=7$ are of less importance.

The relative proportions of output coefficients - illustrated in Table 6-can be read as follows: for product group $j=1$, in each hour, every machine can produce $1.63 \%$ of the overall demand given in Table 5; the other numbers can be interpreted analogously. The next table shows normalized numbers of the state-dependent energy consumption rates.

These numbers are defined as the actual state-dependent energy consumption rates divided by the maximum energy consumption rate regarding all machines; obviously, the fourth machine shows the maximum value in the production state $(i=5)$.

Now, we study sixteen different scenarios $(s=1, \ldots, 16)$ comprising the following weight compositions:

To comply with the company's preferences, the base case $s=1$ is driven by the weighting scheme $w_{1}^{D}>>w_{1}^{Y}=w_{1}^{C}=w_{1}^{E}$. Applying the scenarios $s=2, \ldots, 5$, we put most pressure on each individual objective. Furthermore, we check for pairwise 


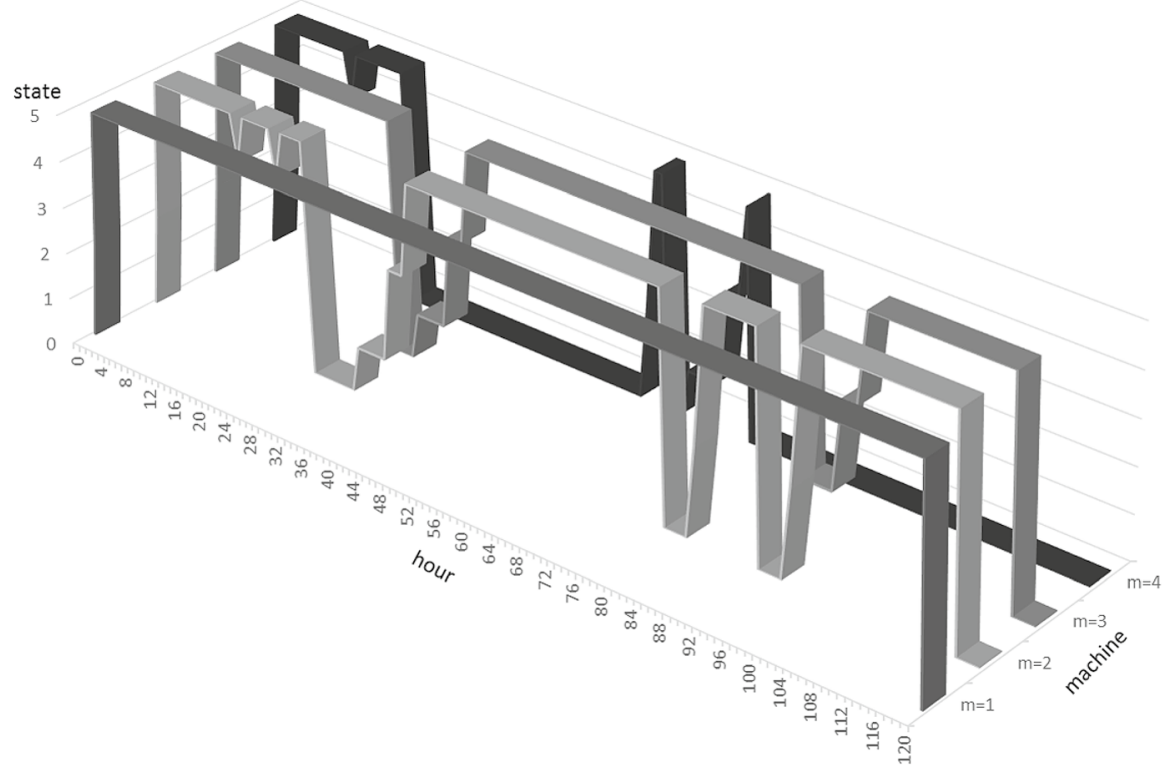

Fig. 8 Machine states for $s=1$

$(s=6, \ldots, 11)$ and group of three $(s=12, \ldots, 15)$ interrelations between the objectives as well as a uniformly distributed weighting scheme $(s=16)$.

The planning horizon covers the next five days and, consequently, we determine the production schedules for the next $T=120 \mathrm{~h}$. In order to study economic potentials of our approach, we use spot prices-so-called Day-Ahead auction pricesfrom the EPEX SPOT SE (European Power Exchange). The daily price curves cover exactly the time period of the company's internal dataset, particularly dating from 24 Sep. 2018 to 28 Sep. 2018. We perform all calculations-via GAMS and CPLEX — on a Windows 10 PC, with an i7-3930K CPU $3.2 \mathrm{GHz}$ and $32 \mathrm{~GB}$ memory. To obtain the results, the overall computation time was about $122 \mathrm{~h}$. Here, the base case $(s=1)$ took approx. 36.6 min with a relative gap of less than $0.1 \%$. Obviously, the remaining scenarios have covered most of the overall computation time. They achieved a relative gap of below $0.01 \%$ each; only the scenarios $s=2, s=6$, $s=7$ and $s=12$ have reached slightly worse relative gaps of approx. $0.78 \%, 0.37$ $\%, 0.04 \%$ and $0.82 \%$ - which are still nearly optimal. All solutions are integral and, hence, there is the presumption that the solver has not yet discovered the optimality of most of the solutions at hand. In the next section, we study and discuss the results of the scenarios. 


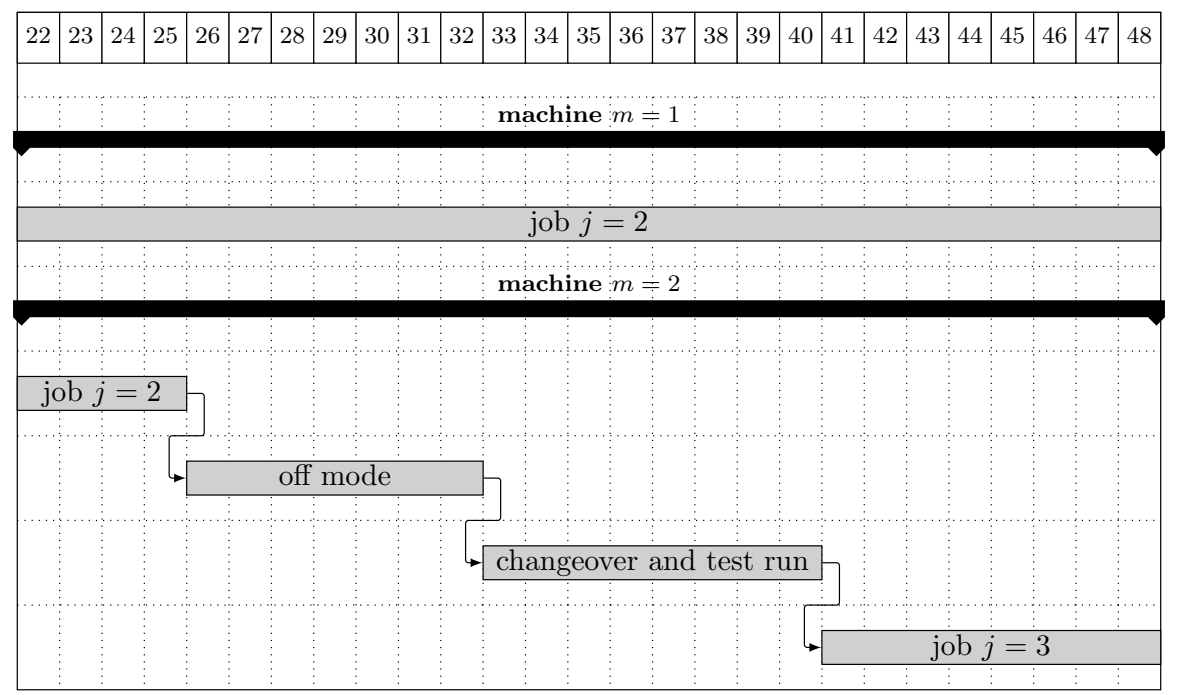

Fig. 9 Partial Gantt-chart for the second day and $s=1$

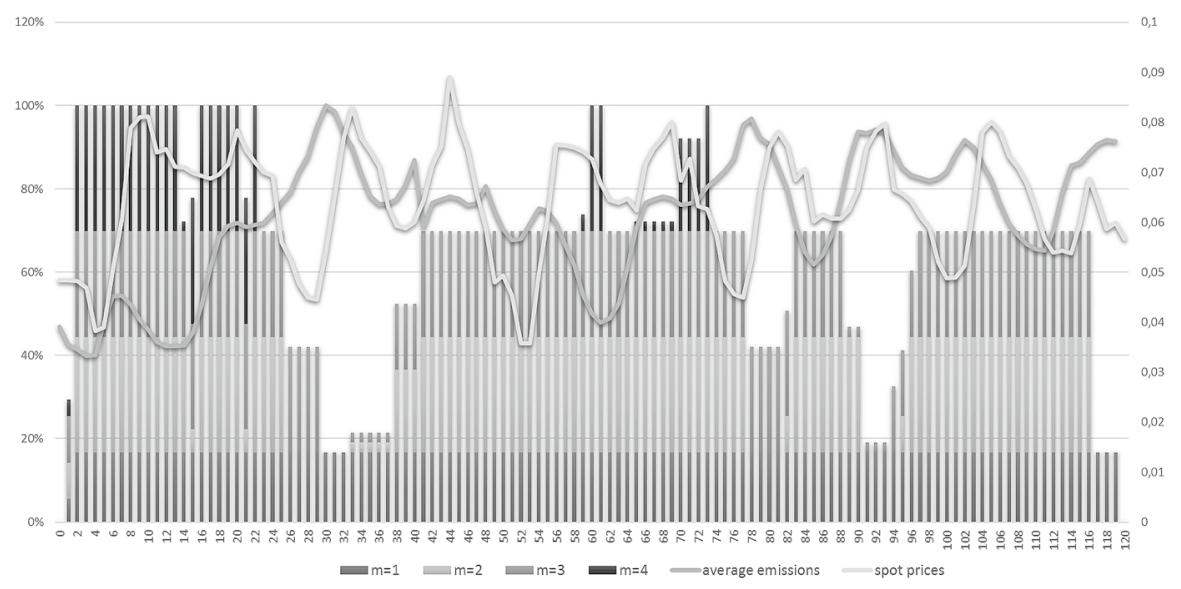

Fig. 10 Cumulative power consumption for $s=1$, spot prices and average emissions

\subsection{Discussion of the findings}

\subsubsection{Scenario analysis}

Solving (23) with regard to our base case (scenario 1), we obtain Figs. 8, 9 and 10.

Figure 8 shows the machine states for the whole planning horizon. Here, due to the fact that machine $m=1$ is relatively new and has the lowest power consumption in production mode, refer to Table 7, it operates continuously. During the first day, 
machine $m=2$ is also in the production state, but then the second day is used to change the equipment. Figure 9 shows a partial Gantt-chart to illustrate these details.

Machine $m=3$ will also be prepared at the second day. Interestingly, machine $m=4$ is often switched off over the whole period of time. This situation is very close to the company's current schedule because machine 4 is the oldest one and requires a large amount of energy, see again Table 7; it only operates if some special products are requested, cf. Table 1, or in the case of an unexpected high demand. To make the economic consequences more transparent, we consider Fig. 10; the presentation of the power level follows the same logic as in Table 7. From an energy-oriented perspective, one can see that the model steers the production states in some unfavourable periods because the second day shows two spot price low points $(t=28$ and $t=38)$. From an ecological point of view, however, the second day is very unattractive due to its emission maximum.

Table 8, which comprises the normalized target achievements for the 16 scenarios, reveals the partially conflicting relations between all goals. Due to our normalization in (23), the best value equals $100 \%$ and the worst value is $0 \%$.

Here, the scenarios $s=5, s=10, s=11$ and $s=15$ lead to almost no production quantities. From a management point of view, these scenarios are unreasonable due to insufficient service of demand; from an ecological perspective, however, such scenarios yield the best outcomes regarding the emissions, of course. This observation might emphasize the omnipresent conflict between economic and ecologic criteria. The scenarios $s=1, s=2$ and $s=7$ indicate a conflict between production quantities and changeovers. To study the impact on production quantities in more detail, Table 9 comprises the relative shortfalls in quantities for selected scenarios.

Table 9 shows that even in the best case $s=2$-from a production point of view-, the company's capacity is too little to meet the demand. That is, even if we focus most strongly on producing goods, the company is unable to fulfill the weekly demand. On the other hand, the worst case scenario is $s=3$; in this case, we only fulfill approx. $68 \%$ of the total demand. Three scenarios $(s=1, s=6$, $s=12$ ) imply shortfalls in three jobs, while scenario $s=2$ causes a shortfall in only two out of seven jobs. In the scenarios $s=3, s=8$ and $s=14$, for example, we are given a shortfall in six jobs. There is only one job which is fully completed over all scenarios; this is job $j=2$. It comprises the most important product type and is the most-sold product of the company.

Returning to the discussion regarding our main conflict, we see that putting more pressure on the energy cost goal and less on the emission target (see $s=1$ and $s=7$ in Table 10) can lead to higher emissions, realizing only moderate energy cost improvements (cf. Table 8). Accordingly, scenarios $s=7$ and $s=12$ provide good solutions in terms of energy costs, but the emission values are rather poor. The opposite is true for the emissions of scenario $s=8$. However, almost ignoring the goals energy costs and emissions leads to the results of scenario $s=6$; here, the energy consumption exceeds the so-called Erheblichkeitsschwelle $b^{\text {thresh }}$ in one of the pre-defined peak load time windows $\mathcal{T}^{\text {peak }}$, thus the energy costs are highest. It is also noteworthy that the scenarios 8,13 , 14 , and 16 yield the same results. In these four scenarios, the production quantity 


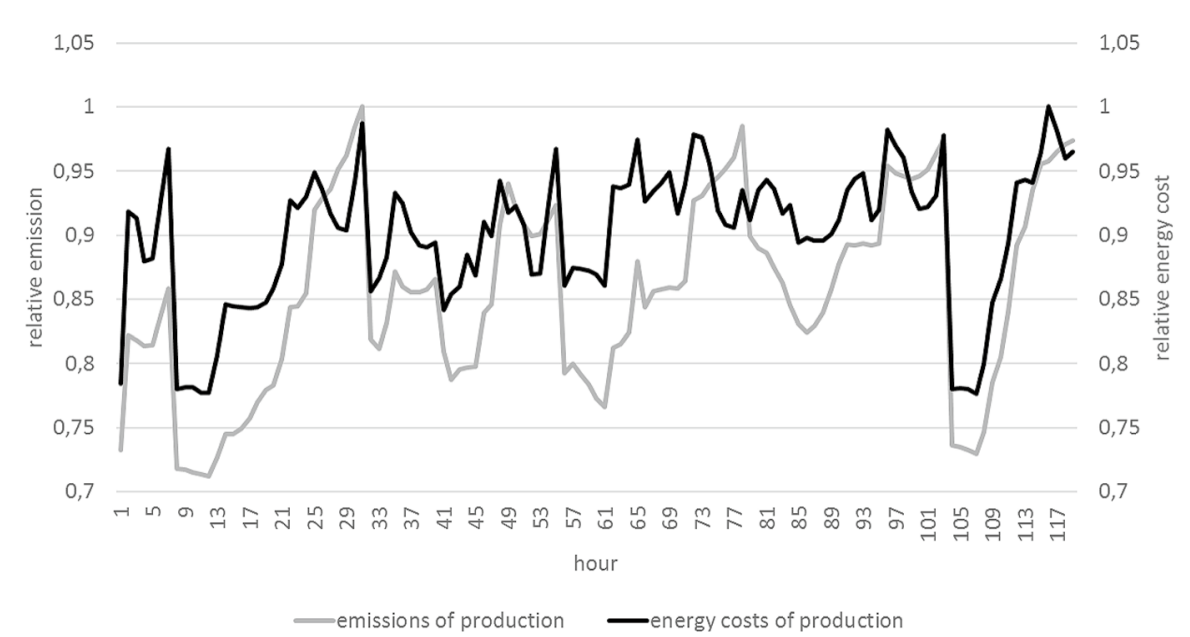

Fig. 11 Relative energy costs vs. relative emissions for $s=7$

Table 7 Normalized energy consumption rates

\begin{tabular}{lllll}
\hline$a_{\text {im }}^{\text {elec }}$ & $m=1$ & $m=2$ & $m=3$ & $m=4$ \\
\hline$i=0$ & 0 & 0 & 0 & 0 \\
$i=1$ & 0.0789 & 0.0789 & 0.0789 & 0.0789 \\
$i=2$ & 0.1842 & 0.2895 & 0.3684 & 0.1316 \\
$i=3$ & 0.3947 & 0.6579 & 0.5263 & 0.7368 \\
$i=4$ & 0.1316 & 0.1842 & 0.2105 & 0.0789 \\
$i=5$ & 0.5526 & 0.9211 & 0.8421 & 1.0000 \\
\hline
\end{tabular}

goal and the emission goal receive a high weight each. Here, it is also interesting to note that the exchange between the time-related one and the energy cost objective obviously has no impact on the outcomes, see again Table 8.

All observations provide a first hint regarding the relationship between energy costs and carbon dioxide emissions. Table 11 presents the upper triangle of linear correlations to illustrate the mutual relationships between the four goals more clearly:

Obviously, there are no perfect linear relationships. The smallest negative score can be found in the second column of the first row; this number indicates a high inverse relation between production quantities and numbers of changeovers. Certainly, this is not surprising. Production quantities and energy costs as well as emissions are also negatively correlated. Surprisingly enough, the results regarding energy costs and emissions are almost linearly uncorrelated; this again supports the hypothesis which we have raised in Sect. 2-a possible conflict between energy costs and average carbon dioxide emissions. Next, to show possible countervailing effects between energy costs and average carbon dioxide emissions, we present Fig. 11. In this figure, the black graph shows the relative energy costs, i.e., the actual energy costs divided by the maximum energy costs realized in scenario $s=7$; the 
Table 8 Degree of goal achievements

\begin{tabular}{lllll}
\hline scenario & $D_{s}^{\text {norm }}$ & $Y_{s}^{\text {norm }}$ & $C_{s}^{\text {norm }}$ & $E_{s}^{\text {norm }}$ \\
\hline $\mathrm{s}=1$ & $95.89 \%$ & $62.35 \%$ & $99.28 \%$ & $83.70 \%$ \\
$\mathrm{~s}=2$ & $100.00 \%$ & $0.00 \%$ & $87.03 \%$ & $33.28 \%$ \\
$\mathrm{~s}=3$ & $59.64 \%$ & $100.00 \%$ & $98.09 \%$ & $85.59 \%$ \\
$\mathrm{~s}=4$ & $20.67 \%$ & $100.00 \%$ & $100.00 \%$ & $17.96 \%$ \\
$\mathrm{~s}=5$ & $3.23 \%$ & $100.00 \%$ & $95.46 \%$ & $100.00 \%$ \\
$\mathrm{~s}=6$ & $96.49 \%$ & $70.59 \%$ & $66.37 \%$ & $63.80 \%$ \\
$\mathrm{~s}=7$ & $98.98 \%$ & $64.71 \%$ & $99.92 \%$ & $1.04 \%$ \\
$\mathrm{~s}=8$ & $88.05 \%$ & $76.47 \%$ & $99.41 \%$ & $86.66 \%$ \\
$\mathrm{~s}=9$ & $27.42 \%$ & $100.00 \%$ & $99.99 \%$ & $22.79 \%$ \\
$\mathrm{~s}=10$ & $7.11 \%$ & $100.00 \%$ & $95.64 \%$ & $99.74 \%$ \\
$\mathrm{~s}=11$ & $0.00 \%$ & $100.00 \%$ & $99.86 \%$ & $97.09 \%$ \\
$\mathrm{~s}=12$ & $96.49 \%$ & $70.59 \%$ & $99.81 \%$ & $0.00 \%$ \\
$\mathrm{~s}=13$ & $88.05 \%$ & $76.47 \%$ & $99.41 \%$ & $86.66 \%$ \\
$\mathrm{~s}=14$ & $88.05 \%$ & $76.47 \%$ & $99.41 \%$ & $86.66 \%$ \\
$\mathrm{~s}=15$ & $0.00 \%$ & $100.00 \%$ & $99.86 \%$ & $97.09 \%$ \\
$\mathrm{~s}=16$ & $88.05 \%$ & $76.47 \%$ & $99.41 \%$ & $86.66 \%$ \\
\hline
\end{tabular}

Table 9 Relative numbers of the shortfall quantities for selected scenarios

\begin{tabular}{lllllllllll}
\hline & $s=1$ & $s=2$ & $s=3$ & $s=6$ & $s=7$ & $s=8$ & $s=12$ & $s=13$ & $s=14$ & $s=16$ \\
\hline shortfall & 0.0336 & 0.0018 & 0.3172 & 0.0345 & 0.0163 & 0.0997 & 0.0345 & 0.0994 & 0.1013 & 0.1009 \\
\hline
\end{tabular}

grey curve follows the same logic but presenting the relative carbon dioxide emissions. Here, energy costs partially diverge from average carbon dioxide emissions in certain periods-namely during the off-peak periods, where the energy mix tends to be less green, see again Fig. 2 in Sect. 1.2.

\subsubsection{Managerial takeaways}

Our business partner was interested in operative instructions and helpful comments derived from our scenario solutions. Ex post, the different scenarios and machine assignments can be compared with one another without any problems. However, time-critical operational planning with current real data from the enterprise resource planning (ERP) system requires that the findings of exemplary scenario analysis can be used directly for decision support avoiding further scenario simulations.

Our approach provides a well-grounded basis for such a decision support, especially in energy intensive industries. It permits an overview of the mutual relationships of the most pertinent aspects in the context of sustainable production planning. Lot sizes and machine schedules can be carefully fine-tuned with respect to changing conditions. 
Table 10 Weighting schemes of all scenarios

\begin{tabular}{lllll}
\hline & $w_{s}^{D}$ & $w_{s}^{Y}$ & $w_{s}^{C}$ & $w_{s}^{E}$ \\
\hline$s=1$ & 0.550 & 0.150 & 0.150 & 0.150 \\
$s=2$ & 0.991 & 0.003 & 0.003 & 0.003 \\
$s=3$ & 0.003 & 0.991 & 0.003 & 0.003 \\
$s=4$ & 0.003 & 0.003 & 0.991 & 0.003 \\
$s=5$ & 0.003 & 0.003 & 0.003 & 0.991 \\
$s=6$ & 0.497 & 0.497 & 0.003 & 0.003 \\
$s=8$ & 0.497 & 0.003 & 0.497 & 0.003 \\
$s=9$ & 0.497 & 0.003 & 0.003 & 0.497 \\
$s=10$ & 0.003 & 0.497 & 0.497 & 0.003 \\
$s=11$ & 0.003 & 0.497 & 0.003 & 0.497 \\
$s=12$ & 0.003 & 0.003 & 0.497 & 0.497 \\
$s=13$ & 0.332 & 0.332 & 0.332 & 0.004 \\
$s=14$ & 0.332 & 0.332 & 0.004 & 0.332 \\
$s=15$ & 0.332 & 0.004 & 0.332 & 0.332 \\
$s=16$ & 0.004 & 0.332 & 0.332 & 0.332 \\
\hline
\end{tabular}

Table 11 Correlations

\begin{tabular}{lllll}
\hline & quantity goal & time-related goal & energy cost goal & emission goal \\
\hline quantity goal $(D)$ & 1.0000 & -0.7169 & -0.2509 & -0.3263 \\
time-related goal $(Y)$ & & 1.0000 & 0.3406 & 0.3369 \\
energy cost goal $(C)$ & & 1.0000 & 0.0167 \\
emission goal $(E)$ & & & 1.0000 \\
\hline
\end{tabular}

A changing condition could look like this. A company, like our business partner, primarily focuses its production on serving weekly customer demand in the best possible way and doing this at the lowest possible energy costs. This would correspond to a target weighting similar to that in scenario $s=7$. The top management now pretends to produce more sustainably and thus to increase the company's reputation. The production management would now face the task of increasing sustainability beyond the heavily weighted minimization of energy costs. A conceivable adjustment of the target would be found in scenario $s=14$. The target adjustment from $s=7$ to $s=14$, for example, implies particular operational effects for the machine assignment of the coming week. From the findings of our case study, the production manager could take away that, at the tolerable expense of satisfying weekly customer demand (cf. Table 9), one could produce much more sustainably (in terms of goal E) with even less set-up times.

The previous example shows that the production manager must finally weigh up which target weighting he/she chooses. In order to be able to recognize the advantages and disadvantages of different options more clearly, it can help to make the 
decision-making environment more flexible. Such a redesign would be the use of a cogeneration unit. We studied the consequences of integrating such a $\mathrm{CU}$ at the request of our business partner. Currently, however, the company effectively uses only the thermal energy for production purposes and sells the electric energy as a by-product of this primary function. In Sect. 3.2, we presented how the decisions regarding the electric energy of the cogeneration unit-sell, own use or a combination of both - can be embedded in the multi-objective optimization problem. Because of the additional flexibility for the production manager the use of a CU also can be seen as a further, rather indirect, measure towards sustainable production.

All results and explanations so far show that minimizing energy costs is a pure economic goal and neither an ecological one. The management of a company should be aware of this fact. To put it more ostensively, the energy price and the average emissions of the associated energy-mix are not always following the same movement. That means, if the energy price is relatively high in a considered time period, the associated average emissions could be relatively low. A company can exploit this fact by shifting specific production processes not only in times of low energy prices, but also in times of low average emissions of the energy-mix.

In the current situation, in summary, where the European power industry is in a transitional phase, focussing only on energy costs can worsen the ecological footprint of a company. In other words, we should always be mindful when creating optimization models for steering production plants sustainably, as this always entails a very complex interplay of different objectives which should be considered carefully.

\section{Conclusions and future research}

In this paper, we present a case study comprising a scheduling and lot-sizing problem of a metal-working company, where the company's goals are mainly determined by four objective functions-namely a production quantity-based goal, a changeover-related time goal, an electrical energy cost goal, and a carbon dioxide emission goal. In such an environment, it is usually assumed that reducing electrical energy costs-e.g. via shifting operations-automatically leads to (more) sustainable production plans. In the present paper, we show that this supposition does not always hold true when facing fluctuating carbon dioxide emissions over the whole day. In particular, we present a (deterministic) mixed integer optimization problem, combining lot-sizing and scheduling under timevarying electric energy costs and time-varying carbon dioxide emissions. In this context, we also allow for self-generation of electricity via a cogeneration uniteither selling this energy or using it for production. However, there is still room for improvement towards modeling; yet, we neglect the heat production process of the cogeneration unit and, hence, further economical and ecological gains. Finally, we discuss all outcomes from a managerial point of view.

However, electricity prices as well as the corresponding relative mix of carbon dioxide emissions are uncertain. Consequently, what are useful methods to provide reliable estimates of both data sets? And how can we deal with dynamic 
lead times in our mixed integer optimization problem? These questions could be interesting pathways for future research.

Funding Open Access funding enabled and organized by Projekt DEAL.

Open Access This article is licensed under a Creative Commons Attribution 4.0 International License, which permits use, sharing, adaptation, distribution and reproduction in any medium or format, as long as you give appropriate credit to the original author(s) and the source, provide a link to the Creative Commons licence, and indicate if changes were made. The images or other third party material in this article are included in the article's Creative Commons licence, unless indicated otherwise in a credit line to the material. If material is not included in the article's Creative Commons licence and your intended use is not permitted by statutory regulation or exceeds the permitted use, you will need to obtain permission directly from the copyright holder. To view a copy of this licence, visit http://creativecommons.org/licen ses/by/4.0/.

\section{References}

Bego A, Li L, Sun Z (2014) Identification of reservation capacity in critical peak pricing electricity demand response program for sustainable manufacturing systems. Int J Energy Res 38:728-736. https://doi.org/10.1002/er.3077

Biel K, Glock C (2016) Systamatic literature review of decision support models for energy-efficient production planning. Comput Indu Eng 101:243-259. https://doi.org/10.1016/j.cie.2016.08.021

Buscher U, Eiba J, Schulz S (2016) Nivellierung von energieleistungsspitzen und ein-/ausschalttechniken in der maschinenbelegungsplanung. In: Keidel J, Jähn H, Fischer M, Burghardt T, Neumann D (eds) Modelle und methoden zur entscheidungsunterstützung für betriebswirtschaftliche Wertschöpfungsprozesse, Dr. Kovac, Hamburg, pp 139-154

Ehrgott M (2005) Multicriteria optimization, 2nd edn. Springer, Berlin, Heidelberg. https://doi. org/10.1007/3-540-27659-9

Fysikopoulos A, Pastras G, Alexopoulos T, Chryssolouris G (2014) On a generalized approach to manufacturing energy efficiency. Int J Adv Manuf Technol 73:1437-1452. https://doi. org/10.1007/s00170-014-5818-3

Gahm C, Denz F, Dirr M, Tuma A (2016) Energy-efficient scheduling in manufacturing companies: a review and research framework. Euro J Oper Res 248:744-757. https://doi.org/10.1016/j. ejor.2015.07.017

Garetti M, Taisch M (2012) Sustainable manufacturing: trends and research challenges. Prod Planning Control 23(1-3):83-104. https://doi.org/10.1080/09537287.2011.591619

Giret A, Trentesaux D, Prabhu V (2015) Sustainability in manufacturing operations scheduling: a state of the art review. J Manuf Syst 37:126-140. https://doi.org/10.1016/j.jmsy.2015.08.002

Gong X, De Pessemier T, Joseph W, Martens L (2015) An energy-cost-aware scheduling methodology for sustainable manufacturing. Procedia CIRP 15:129-134. https://doi.org/10.1016/j.proci r.2015.01.041

Graeber D, Kleine A (2013) The combination of forecasts in the trading of electricity from renewable energy sources. J Business Econ 83:409-435. https://doi.org/10.1007/s11573-013-0660-X

Haapala K, Zhao F, Camelio J, Sutherland J, Skerlos S, Dornfeld D, Jawahir I, Clarens A, Rickli J (2013) A review of engineering research in sustainable manufacturing. J Manuf Sci Eng 135:041013-1041013-16. https://doi.org/10.1115/1.4024040

Hong Z, Chu C, Yu Y (2012) Optimization of production planning for green manufacturing. In: Proceedings of the 9th IEEE international conference on networking, sensing and control April 2012:193196, https://doi.org/10.1109/ICNSC.2012.6204915

Jaehn F (2016) Sustainable operations. Euro J Oper Res 253:243-264. https://doi.org/10.1016/j. ejor.2016.02.046

Johannes C, Wichmann M, Spengler T (2018) Flexible production scheduling with volatile energy rates. In: Fink A, Fügenschuh A, Geiger M (eds) Operations research proceedings 2016, Springer, Cham, pp 489-495, https://doi.org/10.1007/978-3-319-55702-1_65 
Kästner T, Kießling A (2016) Energiewende in 60 Minuten-Ein Reiseführer durch die Stromwirtschaft. Springer, Wiesbaden. https://doi.org/10.1007/978-3-658-11561-6

Keller F, Schönborn C, Reinhart G (2015) Energy-orientated machine scheduling for hybrid flow shops. Procedia CIRP 29:156-161. https://doi.org/10.1016/j.procir.2015.02.103

Kleine A, Ostmeyer J (2018) Multikriterielle produktionsplanung-dilemma energieflexibler Ablaufplanung. In: Corsten H, Gössinger R, Spengler T (eds) Handbuch produktions- und logistikmanagement in wertschöpfungsnetzwerken. De Gruyter Oldenbourg, Berlin, Boston, pp 1081-1112

Kost C, Shammugam S, Jülich V, Nguyen HT, Schlegl T (2018) Levelized cost of electricity renewable energy technologies. Frauenhofer Institute for Solar Energy Systems, March. https://www.ise.fraun hofer.de/content/dam/ise/en/documents/publications/studies/EN2018_Fraunhofer-ISE_LCOE_ Renewable_Energy_Technologies.pdf

Li J, Morrison J, Zhang M, Nakano M, Biller S, Lennartson B (2013) Editorial: automation in green manufacturing. IEEE Trans Auto Sci Eng 10(1):1-4. https://doi.org/10.1109/TASE.2012.2227582

Li J, Sang H, Han Y, Wang C, Gao K (2018) Efficient multi-objective optimization algorithm for hybrid flow shop scheduling problems with setup energy consumptions. J Clean Prod 181:584-598. https:// doi.org/10.1016/j.jclepro.2018.02.004

Mansouri S, Aktas E, Besikci U (2016) Green scheduling of a two-machine flowshop: trade-off between makespan and energy consumption. Euro J Oper Res 248:772-788. https://doi.org/10.1016/j. ejor.2015.08.064

Masmoudi O, Yalaoui A, Ouazene Y, Chehade H (2016) Multi-item capacitated lot-sizing problem in a flow-shop system with energy consideration. IFAC-PapersOnLine 49(12):301-306. https://doi. org/10.1016/j.ifacol.2016.07.621

Merkert L, Harjunkoski I, Isaksson A, Säynevirta S, Saarela A, Sand G (2015) Scheduling and energyindustrial challenges and opportunities. Comput Chem Eng 72:183-198. https://doi.org/10.1016/j. compchemeng.2014.05.024

Moon JY, Shin K, Park J (2013) Optimization of production scheduling with time dependent and machine-dependent electricity cost for industrial energy efficiency. Int J Adv Manuf Technol 68:523-535. https://doi.org/10.1007/s00170-013-4749-8

Mouzon G, Yildirim M (2008) A framework to minimise total energy consumption and total tardiness on a single machine. Int J Sustain Eng 1(2):105-116. https://doi.org/10.1080/19397030802257236

Munda G, Nijkamp P, Rietveld P (1994) Qualitative multicriteria evaluation for environmental management. Ecol Econ 10:97-112. https://doi.org/10.1016/0921-8009(94)90002-7

Paraschiv F, Erni D, Pietsch R (2014) The impact of renewable energies on eex day-ahead electricity prices. Energy Policy 73:196-210. https://doi.org/10.1016/j.enpol.2014.05.004

Pinedo M (2016) Scheduling, 5th edn. Springer, New York. https://doi.org/10.1007/978-3-319-26580-3

Rager M, Gahm C, Denz F (2015) Energy-oriented scheduling based on evolutionary algorithms. Comput Oper Res 54:218-231. https://doi.org/10.1016/j.cor.2014.05.002

Reinhart G, Reinhardt M, Grassl M (2012) Energieflexible Produktionssysteme. wt Werkstattstechnik online Jahrgang 102 H. 9:622-628

Steuer R (1986) Multiple criteria optimization: theory, computation, and application, 1st edn, Wiley, New York, https://doi.org/10.1002/oca.4660100109

StromNEV (2005) Verordnung über die Entgelte für den Zugang zu Elektrizitätsversorgungsnetzen, Stromnetzentgeltverordnung vom 25. Juli 2005 (BGB1. I S. 2225), zuletzt geändert am 23. Dezember 2019 (BGBl. I S. 2935)

T'kindt V, Billaut JC, (2006) Multicriteria scheduling, 2nd edn. Springer, Berlin. https://doi.org/10.1007/ b106275

Wang S, Lu X, Li X, Li W (2015) A systematic approach of process planning and scheduling optimization for sustainable machining. J Clean Prod 87:914-929. https://doi.org/10.1016/j.jclepro.2014.10.008

Wichmann M, Johannes C, Spengler T (2019) An extension of the general lot-sizing and scheduling problem (GLSP) with time-dependent energy prices. J Business Econ 89(6):739-742. https://doi. org/10.1007/s11573-018-0921-9

Wozabal D, Graf C, Hirschmann D (2016) The effect of intermittent renewables on the electricity price variance. OR Spectrum 38:687-709. https://doi.org/10.1007/s00291-015-0395-X

Publisher's Note Springer Nature remains neutral with regard to jurisdictional claims in published maps and institutional affiliations. 